\title{
Effect of grit blasting and subsequent heat treatment on stress rupture property of a Ni-based single-crystal superalloy SGX3
}

\author{
Jinshan $\mathrm{He}^{1} \cdot$ Zhengrong $\mathrm{Yu}^{2} \cdot$ Longfei $^{2} \mathrm{i}^{2} \cdot$ Xitao Wang $^{1,3} \cdot$ Qiang Feng $^{2}$
}

Received: 26 December 2019 / Revised: 29 January 2020 / Published online: 22 April 2020

(c) The Chinese Society for Metals (CSM) and Springer-Verlag GmbH Germany, part of Springer Nature 2020

\begin{abstract}
In the present study, the effect of grit blasting and subsequent heat treatment on the stress rupture properties of a thirdgeneration nickel-based single-crystal superalloy SGX3 sheet was studied. It was found that the stress rupture life of alloy SGX3 sheet at $980^{\circ} \mathrm{C} / 250 \mathrm{MPa}$ was reduced by about $60 \%$ by only vacuum heat treatment at $1100{ }^{\circ} \mathrm{C}$ for $200 \mathrm{~h}$ and further reduced by $20 \%$ and $70 \%$ respectively with grit blasting of $0.3 \mathrm{MPa} / 1 \mathrm{~min}$ and $0.5 \mathrm{MPa} / 2 \mathrm{~min}$ before heat treatment. The microstructure analysis results indicated that the degradation of stress rupture life of alloy SGX3 sheet by vacuum heat treatment was mainly attributed to the variation of $\gamma / \gamma^{\prime}$ microstructure, i.e., the decrease in $\gamma^{\prime}$ volume fraction and the coarsening of $\gamma^{\prime}$ precipitates. Furthermore, such degradation by grit blasting and subsequent vacuum heat treatment should be attributed to the formation of cellular recrystallization with different thicknesses at the surface of alloy SGX3 sheet, which not only acts as the vulnerable site for cracks to initiate and propagate but also reduces the effective loading area.
\end{abstract}

Keywords Ni-based single-crystal superalloy $\cdot$ Creep life $\cdot$ Degradation $\cdot$ Recrystallization

\section{Introduction}

Ni-based superalloys are often used for high-pressure turbine blades of advanced aero engines [1-5]. Among these, singlecrystal alloys have been introduced due to their excellent high-temperature mechanical properties by eliminating grain boundaries $[3,6]$. Both thermal stress by temperature gradient during casting and mechanical stress caused by surface processing such as shot peeing or grit blasting lead to the

Available online at https://link.springer.com/journal/40195.

Longfei $\mathrm{Li}$

lilf@skl.ustb.edu.cn

1 Beijing Advanced Innovation Center for Material Genome Engineering, Collaborative Innovation Center of Steel Technology, University of Science and Technology Beijing, Beijing 100083, China

2 Beijing Advanced Innovation Center for Material Genome Engineering, State Key Laboratory for Advanced Metals and Materials, University of Science and Technology Beijing, Beijing 100083, China

3 Shandong Provincial Key Laboratory for High Strength Lightweight Metallic Materials, Advanced Materials Institute, Qilu University of Technology (Shandong Academy of Sciences), Jinan 250353, China local plastic deformation [7-9]. At those sites, the equiaxed recrystallization can occur when Ni-based single-crystal superalloy is further heat-treated at solution temperature [10, 11]. As a result, the transverse grain boundaries introduced by recrystallization lead to the degradation of creep property of Ni-based single-crystal superalloy. Jo et al. reported that the recrystallized grains grew preferentially in the dendritic core and early crack initiation on grain boundaries of surface recrystallization caused a relatively high creep rate in alloy CMSX-2 at $982{ }^{\circ} \mathrm{C}, 240 \mathrm{MPa}[12,13]$. Meng et al. found that creep rupture life shows a sharp decrease with increase in recrystallized depth in a Ni-based superalloy deformed by shot peening [14]. While cellular recrystallization consisting of $\gamma$ phase, $\gamma^{\prime}$ phase and TCP phases may form when the $\mathrm{Ni}$-based superalloy is subjected to lower temperature during service, threatening the safe operation of blades. For instance, it is reported that cellular microstructure of different thicknesses formed on a Ni-based superalloy containing $\mathrm{Re}$ and $\mathrm{Ru}$ after grit blasting and then heat treatment at $1100{ }^{\circ} \mathrm{C}$ [15]. Local stress facilitated cellular recrystallization on single-crystal superalloy accompanied with formation of twin structure and TCP phase during annealing at sub-solvus temperature [16]. Therefore, it is necessary to investigate the effect of cellular recrystallization on stress rupture property for Ni-based single-crystal superalloy. 
More recent studies have identified the degradation effect of recrystallization on creep resistance of Ni-based superalloy $[17,18]$. Xie et al. reported an almost linear reduction of the creep rupture life with the increase in the local recrystallized depth for directionally solidified Ni-based superalloy and suggested that the transverse recyclized grain boundary is a vulnerable site of crack initiation and propagation [19]. In addition, Xiong et al. reported that the stress rupture life of a Ni-based superalloy with cellular recrystallization reduces slightly than that with equiaxed recrystallization after grit blasting and heat treatment by using the round bar specimens. However, most of the turbine engines are thinwalled components, even as $0.5-1.0 \mathrm{~mm}$ thickness [20-22]. The ratio of cellular colony area for round bars and sheet specimens should be different even though the manufacturing process is same. Consequently, the effect of grit blasting on the stress rupture properties for the two types is not the same. Furthermore, few studies have distinguished the separate effects of degraded $\gamma^{\prime}$ phase (i.e., the decrease in $\gamma^{\prime}$ volume fraction and the coarsening of $\gamma^{\prime}$ precipitates) and recrystallization induced by the subsequent heat treatment after grit blasting on creep properties quantitatively.

In the present work, to investigate grit blasting effect on the stress rupture property for a third-generation $\mathrm{Ni}$-based single-crystal superalloy SXG3, different grit blasting processes are used to induce various plastic deformation at surface for sheet materials. After heat treatment at $1100{ }^{\circ} \mathrm{C}$ in vacuum to mimic the serving temperature, the stress rupture properties for different specimens were tested and the corresponding microstructures before and after creep tests were characterized by scanning electron microscopy (SEM) and electron backscattered diffraction (EBSD). Bare specimens and specimens just heat-treated at $1100{ }^{\circ} \mathrm{C}$ in vacuum are also investigated for comparison.

\section{Experimental}

The nominal composition (wt $\%$ ) of the investigated thirdgeneration single-crystal superalloy is $\mathrm{Ni}-12.0 \mathrm{Co}-4.0 \mathrm{Cr}$ 2.0Mo-6.0W-7.0Ta-5.0Re-5.0Al-0.15Hf-0.02C. The single-crystal bars grown along [001] orientation within $5^{\circ}$ were cast by Bridgeman method and then were subjected to standard heat treatment $\left(1300^{\circ} \mathrm{C} / 4 \mathrm{~h}, \mathrm{AC}+1100^{\circ} \mathrm{C} / 4 \mathrm{~h}\right.$, $\mathrm{AC}+870^{\circ} \mathrm{C} / 16 \mathrm{~h}, \mathrm{AC}$ (air cooling)). The single-crystal bars were machined into the sheet specimens for stress rupture tests, whose geometry is illustrated in Fig. 1. To investigate the effect of grit blasting on stress rupture properties, specimens with different processing were designed as shown in Table 1. Specimens GH1 and GH2 were grit-blasted at pressure of $0.3 \mathrm{MPa}$ for $1 \mathrm{~min}$ and $0.5 \mathrm{MPa}$ for $2 \mathrm{~min}$, respectively. Subsequently, they were sealed in silica glass tubes and heat-treated in vacuum at $1100{ }^{\circ} \mathrm{C}$ for $200 \mathrm{~h}$. In addition,

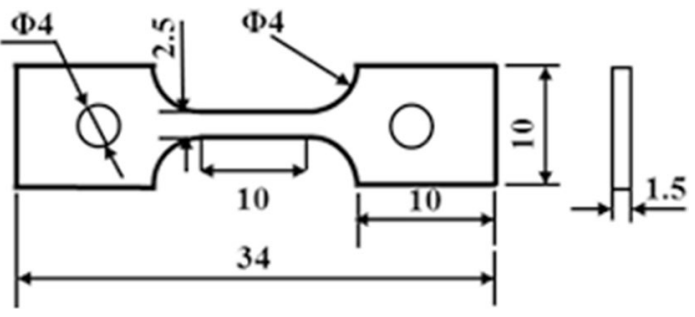

Fig. 1 Geometry of creep rupture testing specimen (mm)

Table 1 Specimens with different grit blasting

\begin{tabular}{llll}
\hline No & $\begin{array}{l}\text { Standard heat } \\
\text { treatment }\end{array}$ & Grit blasting & Vacuum heat treatment \\
\hline $\mathrm{SH}$ & $\sqrt{ }$ & & \\
$\mathrm{VH}$ & $\sqrt{ }$ & $1100^{\circ} \mathrm{C} / 200 \mathrm{~h}$ \\
$\mathrm{GH} 1$ & $\sqrt{ }$ & $0.3 \mathrm{MPa} / 1 \mathrm{~min}$ & $1100^{\circ} \mathrm{C} / 200 \mathrm{~h}$ \\
$\mathrm{GH} 2$ & $\sqrt{ }$ & $0.5 \mathrm{MPa} / 2 \mathrm{~min}$ & $1100^{\circ} \mathrm{C} / 200 \mathrm{~h}$ \\
\hline
\end{tabular}

bare specimens SH with standard heat treatment and specimens VH heat-treated in vacuum at $1100{ }^{\circ} \mathrm{C}$ for $200 \mathrm{~h}$ after the standard heat treatment were prepared. For each processing, at least two stress rupture tests were conducted at $980^{\circ} \mathrm{C} / 250 \mathrm{MPa}$.

Microstructures for different grit blasting before and after stress rupture tests were observed by SEM. The orientations for recrystallized grains near the fracture surface were characterized with EBSD. Metallographic specimens were prepared by grinding with 240-2000\# grind paper and polishing with $\mathrm{Al}_{2} \mathrm{O}_{3}$. The polished specimens were etched with the liquid consisting of 1 vol.\% $\mathrm{HF}, 33$ vol. $\% \mathrm{HNO}_{3}, 33$ vol. $\%$ $\mathrm{CH} 3 \mathrm{COOH}$ and $33 \mathrm{vol} . \% \mathrm{H}_{2} \mathrm{O}$.

\section{Results}

The microstructures and the result of related statistical analysis for different specimens before stress rupture tests are presented in Fig. 2 and Table 2, respectively. As shown in Fig. 2a, 64.0 vol. $\%$ cuboidal $\gamma^{\prime}$ precipitates distributed regularly in $\gamma$ matrix for specimen $\mathrm{SH}$. For specimen $\mathrm{VH}$, the $\gamma^{\prime}$ precipitates coarsened and connected, as shown in Fig. $2 \mathrm{~b}$. The $\gamma^{\prime}$ volume fractions of specimen VH was $40.6 \%$, smaller than $60 \%$ of specimen SH. For specimens GH1 and $\mathrm{GH} 2$, cellular recrystallization consisting of $\gamma$ phase, $\gamma^{\prime}$ phase and TCP phase formed at surface, as shown in Fig. 2c, d. The average thickness of cellular recrystallization in specimen GH2 was $49.6 \pm 4.2 \mu \mathrm{m}$, larger than $18.4 \pm 1.9 \mu \mathrm{m}$ in specimen GH1. The formation of cellular colonies should be attributed to the occurrence of cellular recrystallization below $\gamma^{\prime}$ solvus temperature driven by the stored energy of 


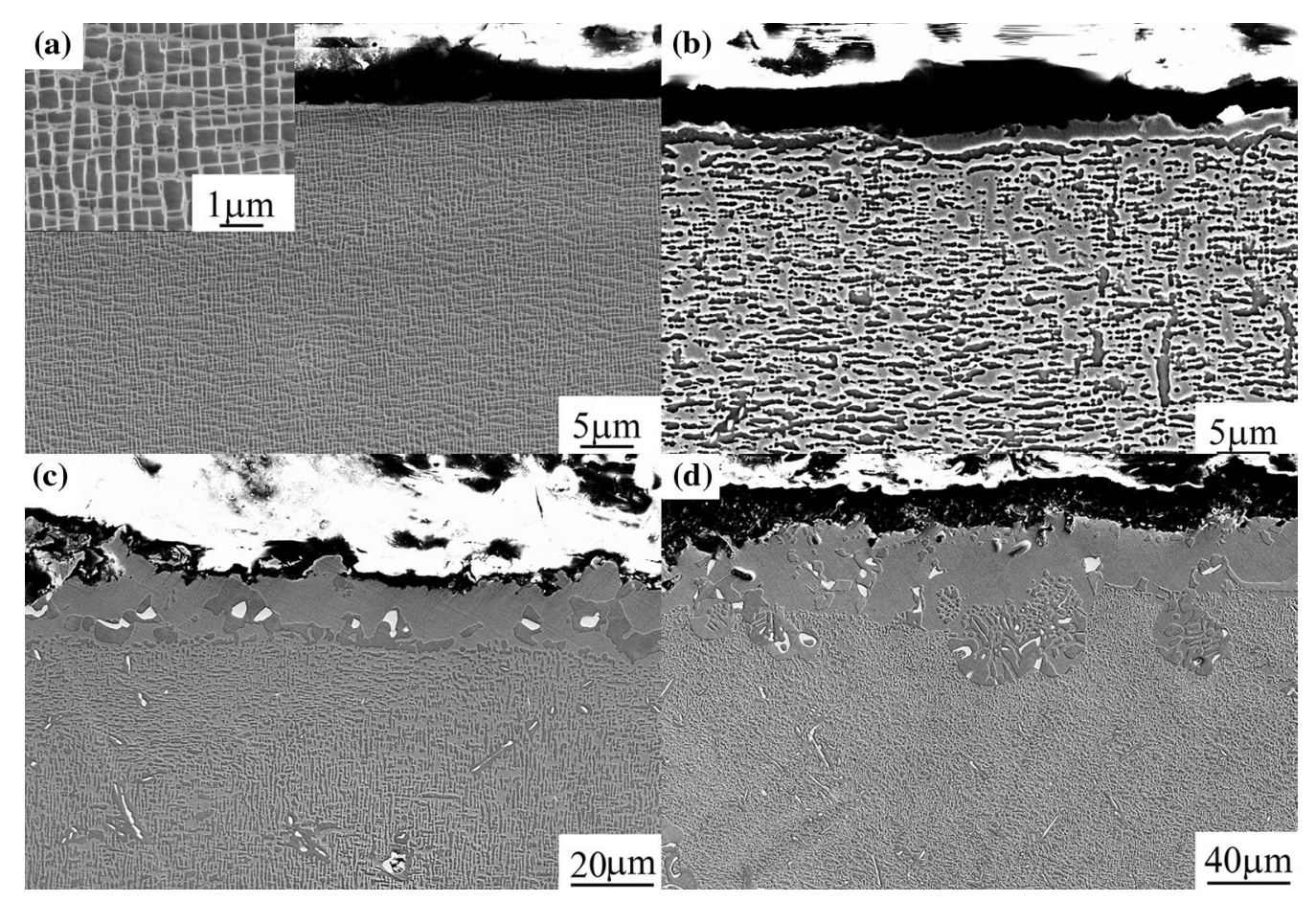

Fig. 2 Microstructures of different specimens before stress rupture tests: a specimen SH; b specimen VH; c specimen GH1; d specimen GH2

Table 2 Statistical analysis of microstructures for different specimens

\begin{tabular}{lllll}
\hline Specimen & $\begin{array}{l}\text { Thickness of cellular } \\
\text { recrystallization } \mu(\mu \mathrm{m})\end{array}$ & $\begin{array}{l}\text { Area of cellular recrystal- } \\
\text { lization }\left(\times 10^{5} \mu \mathrm{m}^{2}\right)\end{array}$ & $\begin{array}{l}\text { Effective loading } \\
\text { area }(\%)\end{array}$ & $\begin{array}{l}\text { Volume } \\
\text { fraction of } \gamma^{\prime} \\
(\text { vol. } \%)\end{array}$ \\
\hline $\mathrm{SH}$ & $0 \pm 0$ & 0 & 100 & 64.0 \\
$\mathrm{VH}$ & $0 \pm 0$ & 0 & 100 & 40.6 \\
$\mathrm{GH} 1$ & $18.4 \pm 1.9$ & 1.5 & 96.1 & 40.1 \\
$\mathrm{GH} 2$ & $49.6 \pm 4.2$ & 4.0 & 89.4 & 40.0 \\
\hline
\end{tabular}

plastic deformation caused by grit blasting [21, 22]. Thus, the increase in grit blasting intensity usually leads to an increase in the thickness of cellular recrystallization [13, 23]. The $\gamma^{\prime}$ volume fractions of the matrix in specimens $\mathrm{GH} 1$ and $\mathrm{GH} 2$ were around $40 \%$, similar with that of specimen VH. Since the intrinsic strength of the cellular recrystallization is much lower than the original $\gamma / \gamma^{\prime}$ microstructure leading to the loss of load bearing area, the effective loading area was defined as the ratio of the area without cellular recrystallization over the whole transverse area [23, 24]. With the thickness of cellular recrystallization, the effective loading area fractions for specimens $\mathrm{GH} 1$ and $\mathrm{GH} 2$ were calculated to be 96.1 and $89.4 \%$, respectively. Both the change of $\gamma / \gamma^{\prime}$ microstructure and the formation of cellular recrystallization would affect the creep resistance of the used single-crystal superalloy.

Figure 3 shows the stress rupture life values for specimens subjected to different grit blasting and heat treatments. The rupture life for specimen $\mathrm{SH}$ was $589.2 \mathrm{~h}$. For specimen $\mathrm{VH}$, it was drastically decreased to $230.5 \mathrm{~h}$ due to the additional vacuum heat treatment. Compared to specimen VH, the rupture lives of specimens $\mathrm{GH} 1$ and $\mathrm{GH} 2$ were decreased by about $20 \%$ and $70 \%$, respectively, i.e., $186.9 \mathrm{~h}$ and $73.4 \mathrm{~h}$, respectively, due to the formation of cellular recrystallization on the surface.

The microstructures away from and near fracture surfaces for different specimens after stress rupture tests are shown in Figs. 4 and 5. Obviously, the $\gamma$ ' precipitates in specimen SH had turned to derafting due to the long creep life. For other specimens, there was no obvious rafting structure and the $\gamma$ ' precipitates coarsened and linked with each other since rupture lives for those specimens were short, as presented in Fig. 4b-d. As shown in Fig. 5a, there were only 2 cracks at surface within $2 \mathrm{~mm}$ away from fracture surface for specimen SH with lots of microvoids inside. Similar microstructure feature was presented in specimen $\mathrm{VH}$ with only a 


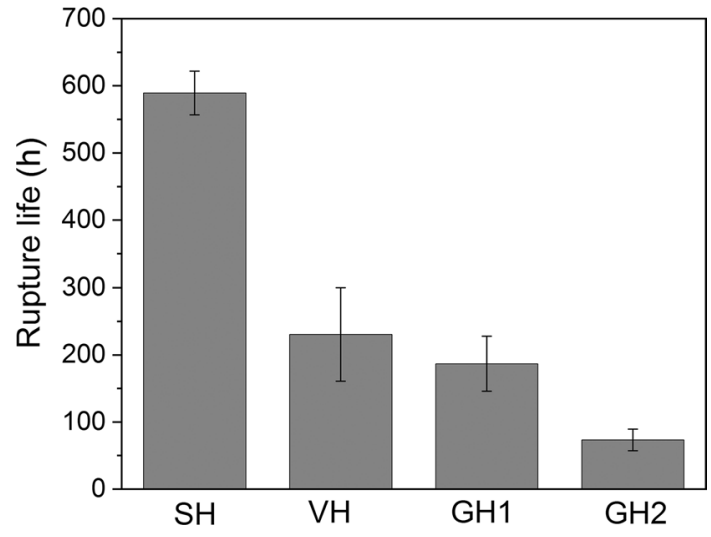

Fig. 3 Rupture life values for specimens with different heat treatments and grit blasting

surface microcrack, as presented in Fig. 5b. However, there were much more cracks, 17 and 18 cracks along transverse direction for specimens $\mathrm{GH} 1$ and $\mathrm{GH} 2$, respectively, shown in Fig. 5c, d. The length of those cracks were also longer than those in specimens $\mathrm{SH}$ and VH. In addition, multiple voids were also formed in specimens $\mathrm{GH} 1$ and $\mathrm{GH} 2$, which were likely to be induced by the propagation of cracks at surface. To further analyze the initiation and propagation of cracks at surface, EBSD images with orientation information are presented in Fig. 6. It was found that for the specimen without grit blasting, there was almost no misorientation chaos inside the specimen except for few tips of microcracks, as shown in Fig. 6a, while the misorientations in cellular recrystallization at surface were different with that in the matrix, as shown in Fig. 6b, indicating the existence of recrystallization. Furthermore, most of retained cracks located along the grain boundaries inside the cellular recrystallization or between the matrix and cellular colony, illustrating that the cracks were easy to initiate and propagate at grain boundaries.

\section{Discussion}

With the above results, the average stress rupture life of specimen $\mathrm{VH}$ was about $230 \mathrm{~h}$, which was reduced by about $60 \%$ of that of specimen $\mathrm{SH}$ at $980{ }^{\circ} \mathrm{C} / 250 \mathrm{MPa}$. The creep rupture property is largely dependent on the volume fraction, morphology and size of $\gamma^{\prime}[25,26]$. As indicated, the $\gamma^{\prime}$ volume fraction decreased to $41 \%$ and $\gamma^{\prime}$ precipitates coarsened and linked together in specimen VH. Consequently, the rupture life of specimen $\mathrm{VH}$ was much shorter than that of

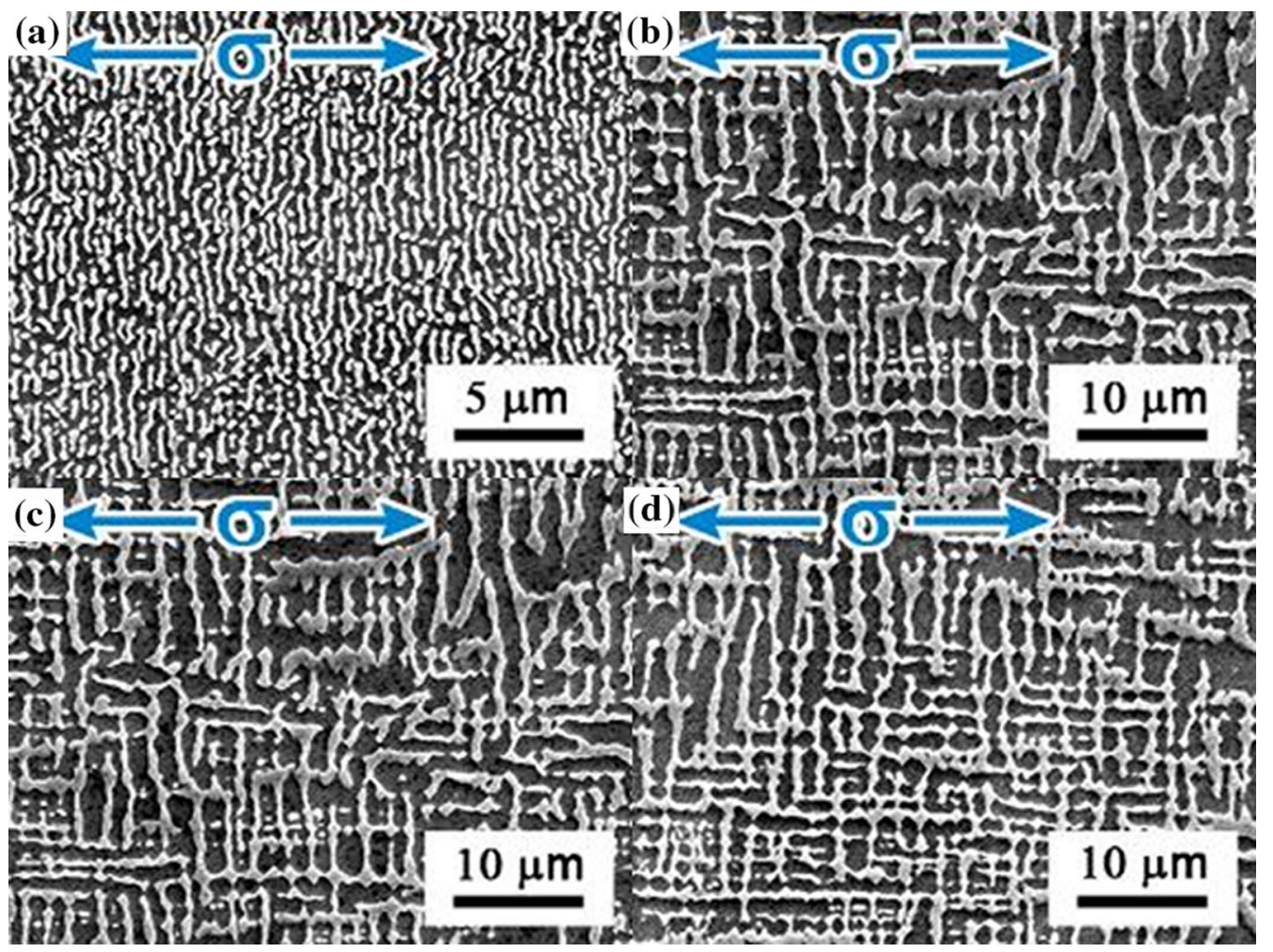

Fig. 4 Microstructures of longitude sections with $4 \mathrm{~mm}$ away from fracture surfaces for different specimens after stress rupture tests: a specimen $\mathrm{SH}$; b specimen $\mathrm{VH}$; c specimen GH1; d specimen $\mathrm{GH} 2$ 


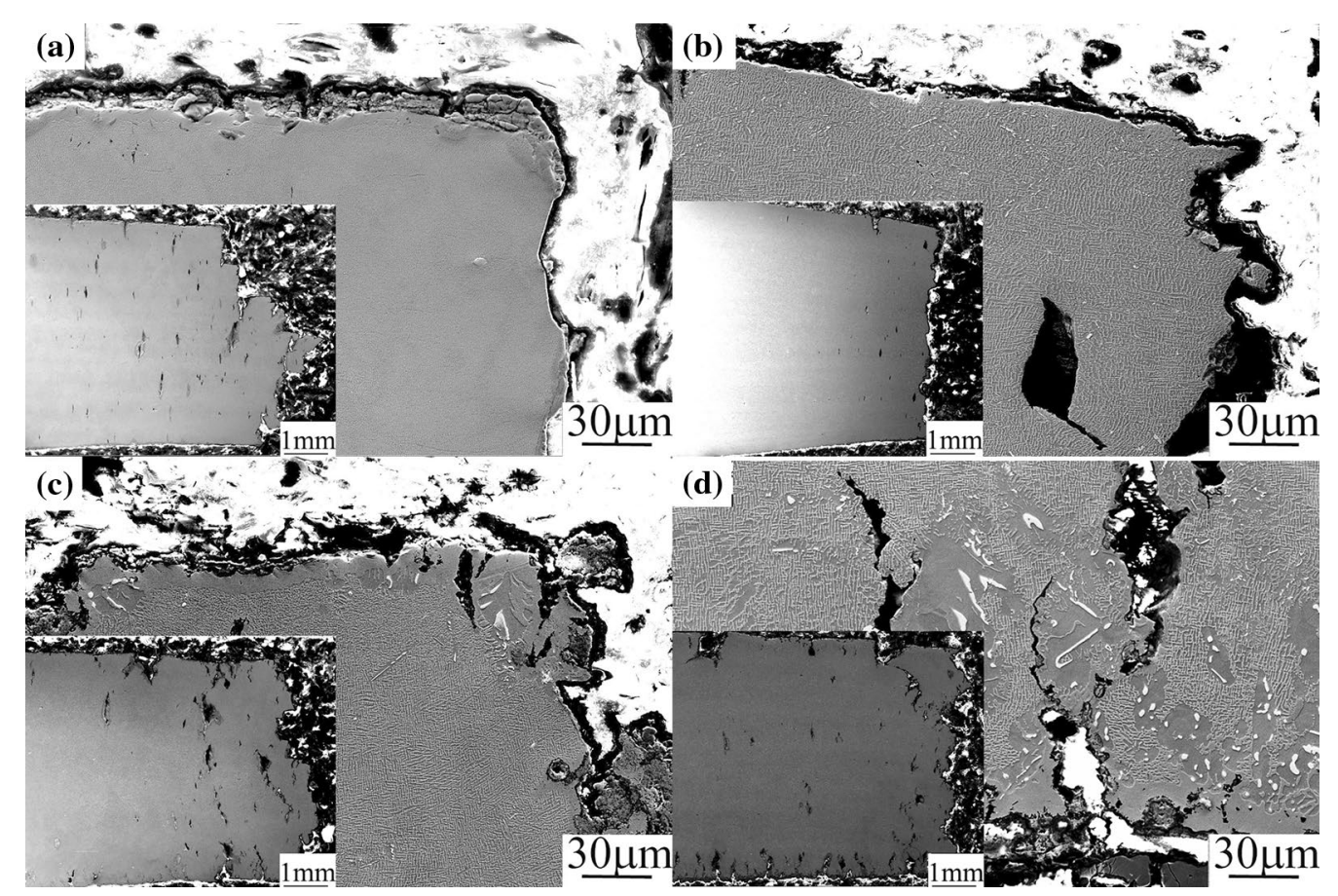

Fig. 5 Microstructures of longitude sections near fracture surfaces for different specimens after stress rupture tests: a specimen SH; b specimen $\mathrm{VH}$; c specimen GH1; d specimen GH2 (the insets are of small magnifications)

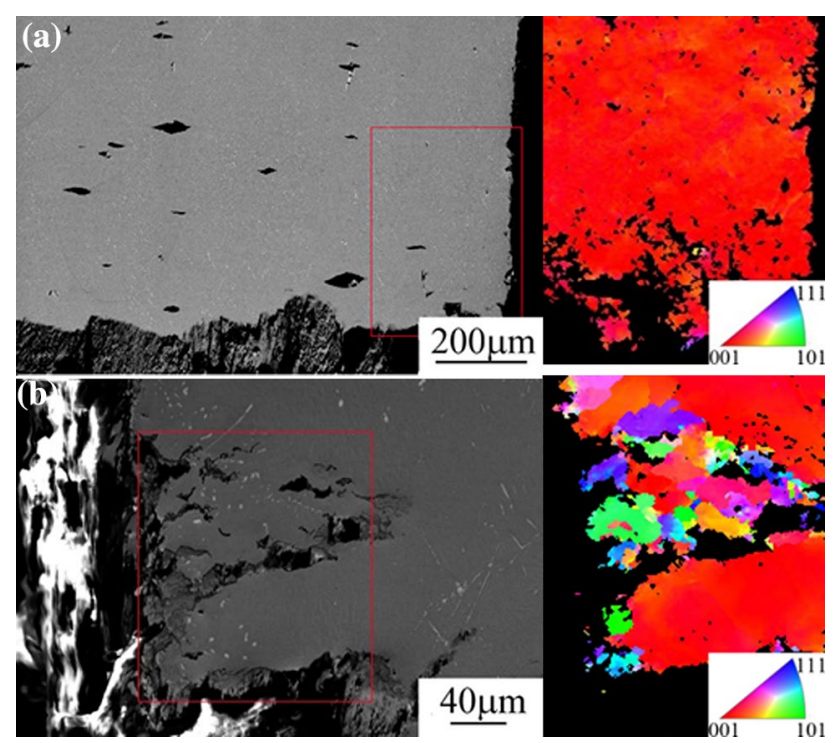

Fig. 6 Morphologies of retained cracks and corresponding loading direction inverse pole figure maps for different specimens after stress rupture tests: a specimen $\mathrm{VH}, \mathbf{b}$ specimen $\mathrm{GH} 2$

specimen $\mathrm{SH}$ and there was no time for $\gamma^{\prime}$ phase in specimen VH to rafting.

Moreover, the formation of cellular recrystallization led to the further degradation of stress rupture life of alloy SGX3 sheet. The rupture lives of specimens GH1 and GH2 were reduced by $20 \%$ and $70 \%$, respectively, compared to specimen VH without grit blasting. Although those specimens had similar degraded matrix microstructures, specimens GH1 and GH2 had additional cellular recrystallization consisting of irregular $\gamma^{\prime}, \gamma$ and TCP phases at the surface, which did not have the same strengthening effect as the matrix. As a result, cracks were easy to initiate and propagate along grain boundaries in cellular recrystallization during creep, as shown in Figs. 4 and 5. What is more, the thickness of cellular recrystallization in specimen GH2 was larger than that in specimen GH1. The thicker the cellular recrystallization, the smaller the effective loading area. Accordingly, compared to specimen GH1, specimen GH2 was subjected to larger stress during creep and the stress rupture life was shorter.

By assuming that cellular recrystallization does not bear any stress during creep, the effects of grit blasting and subsequent heat treatment on stress rupture property of alloy SGX3 sheet are summarized in Fig. 7. The additional vacuum heat treatment led to the decrease in $\gamma^{\prime}$ volume fraction and the coarsening of $\gamma^{\prime}$ precipitates, resulting in the weakened $\gamma^{\prime}$ strengthening effect, as indicated by the blue dash line in Fig. 7. Apart from the microstructure degradation, the formation of cellular recrystallization in specimens by grit blasting and subsequent heat treatment led to the further degradation of stress rupture property, as indicated by the red dash line in Fig. 7, since the stress the matrix bear was increased in some extent with the decrease in effective loading area. Moreover, the cracks were easy to initiate and 


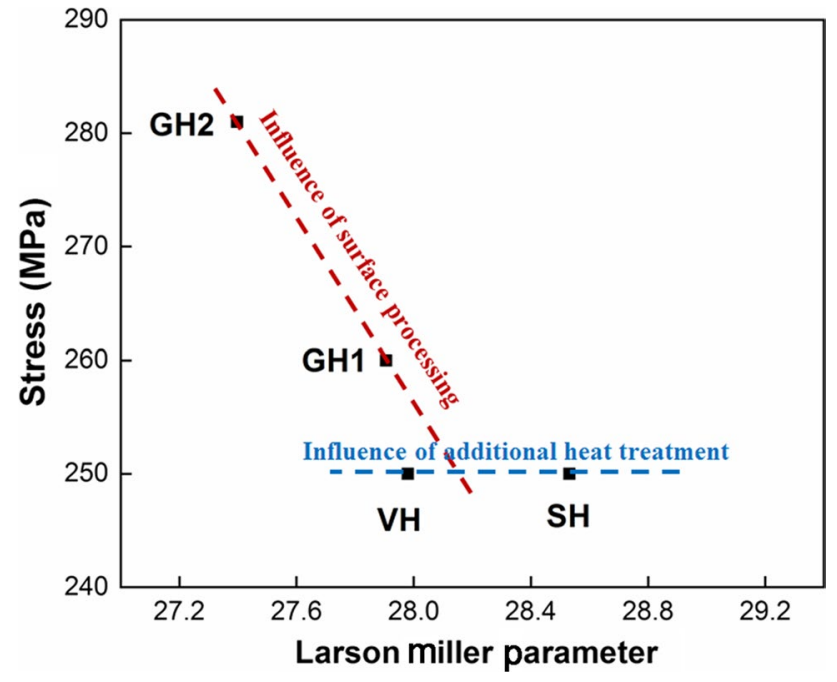

Fig. 7 Effects of grit blasting and subsequent heat treatment on stress rupture property of alloy SGX3 sheet

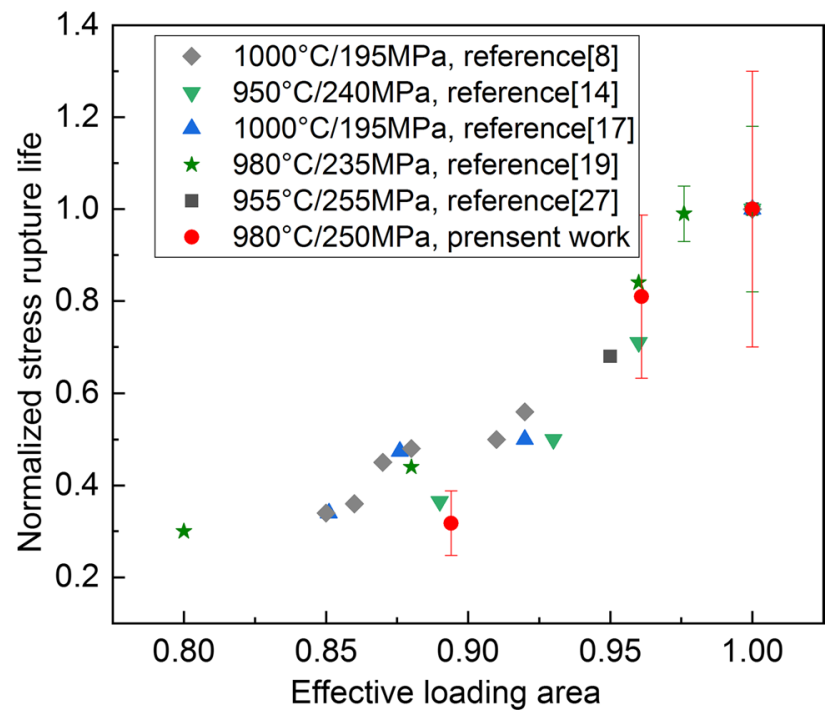

Fig. 8 Illustration of surface recrystallization on stress rupture life for different Ni-based superalloys propagate in those areas during creep. It is worthy to be noted that the intersection of the red line and blue line lies on the right of specimen $\mathrm{VH}$, indicating that the cellular recrystallization at surface may bear some stress during loading.

The recrystallization depth influence on stress rupture life for other superalloys and the current alloy is summarized as shown in Fig. 8, and the related information is presented in Tables 3 and 4. Obviously, the normalized stress rupture life shows an almost linear reduction with the increase in the local recrystallization depth and a decrease of $\sim 5 \%$ effective loading area generally leads to a drop of $30 \%$ to $40 \%$ in the creep rupture life for both directionally solidified Ni-based superalloys and other single-crystal superalloys $[8,14,17,19,27]$. This seems that the recrystallization depth has similar influence on the stress rupture properties of different alloys, since the surface recrystallization not only reduces the effective loading area but also acts as the vulnerable site for crack initiation and propagation. In addition, it is also noted that the recrystallization type does not seem to have pronounced influence on the stress rupture properties as the figure shows a similar trend for the creep rupture properties with the increasing depth of the equiaxed or cellular recrystallization. Further research combing with FEM simulation should be conducted to analyze the strength of surface recrystallization in different alloys, for providing a guidance on evaluation of safe operation for turbine blades.

\section{Conclusions}

In the present study, the third-generation Ni-based singlecrystal superalloy SXG3 sheet was surface processed by grit blasting of $0.3 \mathrm{MPa} / 1 \mathrm{~min}$ or $0.5 \mathrm{MPa} / 2 \mathrm{~min}$ and subsequently vacuum heat-treated at $1100{ }^{\circ} \mathrm{C}$ for $200 \mathrm{~h}$. The effects of grit blasting and heat treatment on stress rupture life at elevated temperature were investigated. The conclusions can be summarized as follows:

(1) By vacuum heat treatment at $1100{ }^{\circ} \mathrm{C}$ for $200 \mathrm{~h}, \gamma^{\prime}$ volume fraction decreased and $\gamma^{\prime}$ precipitates coarsened in alloy SGX3 sheet, resulting in the reduction of stress rupture life at $980{ }^{\circ} \mathrm{C} / 250 \mathrm{MPa}$ by about $60 \%$, compared to the specimen by the standard heat treatment, i.e., $230.5 \mathrm{~h}$ versus $589.2 \mathrm{~h}$.

Table 3 Chemical composition (wt\%) of alloys in Refs.[8, 14, 17, 19, 27]

\begin{tabular}{llllllllllll}
\hline References & $\mathrm{Ni}$ & $\mathrm{Cr}$ & $\mathrm{Co}$ & $\mathrm{W}$ & $\mathrm{Mo}$ & $\mathrm{Al}$ & $\mathrm{Ti}$ & $\mathrm{Ta}$ & $\mathrm{C}$ & $\mathrm{B}$ & $\mathrm{Nb}$ \\
\hline$[8]$ & $\mathrm{Bal}$ & 8.5 & 5 & 9.5 & - & 5.5 & 2.2 & 2.8 & 0.02 & - & $\mathrm{Hf}$ \\
{$[14]$} & $\mathrm{Bal}$ & 8 & 5 & 5 & 2 & 6 & 2 & 3 & - & - & - \\
{$[17]$} & $\mathrm{Bal}$ & $8-10$ & $9-11$ & $11.5-12.5$ & - & $4.75-5.25$ & $1.75-2.25$ & - & $0.12-0.16$ & $0.01-0.02$ & $0.75-1.25$ \\
{$[19]$} & $\mathrm{Bal}$ & 8.9 & 10 & 11.7 & - & 5 & 2 & 1 & - & 0.014 & 1 \\
{$[27]$} & $\mathrm{Bal}$ & 9 & 10 & 7 & 2 & 5 & 3.5 & 4 & 0.1 & 0.01 & - \\
\hline
\end{tabular}


Table 4 Creep information of alloys in Refs.[8, 14, 17, 19, 27]. The normalized stress rupture life is defined as the ratio of the stress rupture life time of a specimen over that of the same alloy without recrystallization at the same creep condition

\begin{tabular}{|c|c|c|c|c|c|}
\hline References & Alloy & Creep condition & Recrystallization type & $\begin{array}{l}\text { Effective loading } \\
\text { area }(\%)\end{array}$ & $\begin{array}{l}\text { Normalized } \\
\text { stress rupture } \\
\text { life }\end{array}$ \\
\hline [19] & Directionally solidified & $980^{\circ} \mathrm{C} / 235 \mathrm{MPa}$ & Not indicated & $\begin{array}{l}1 \\
0.98 \\
0.96 \\
0.88 \\
0.8\end{array}$ & $\begin{array}{l}1 \pm 0.18 \\
0.99 \pm 0.06 \\
0.84 \\
0.44 \\
0.3\end{array}$ \\
\hline [27] & Directionally solidified & $955^{\circ} \mathrm{C} / 255 \mathrm{MPa}$ & Equiaxed & $\begin{array}{l}1 \\
0.95\end{array}$ & $\begin{array}{l}1 \\
0.68\end{array}$ \\
\hline [8] & Single crystal & $1000^{\circ} \mathrm{C} / 195 \mathrm{MPa}$ & Equiaxed & $\begin{array}{l}1 \\
0.92 \\
0.91 \\
0.88 \\
0.87 \\
0.86 \\
0.85\end{array}$ & $\begin{array}{l}1 \\
0.56 \\
0.5 \\
0.48 \\
0.45 \\
0.36 \\
0.34\end{array}$ \\
\hline [14] & Single crystal & $950^{\circ} \mathrm{C} / 240 \mathrm{MPa}$ & Equiaxed & $\begin{array}{l}1 \\
0.96 \\
0.93 \\
0.89\end{array}$ & $\begin{array}{l}1 \\
0.71 \\
0.5 \\
0.365\end{array}$ \\
\hline [17] & Single crystal & $1000^{\circ} \mathrm{C} / 195 \mathrm{MPa}$ & Not indicated & $\begin{array}{l}1 \\
0.92 \\
0.876 \\
0.851\end{array}$ & $\begin{array}{l}1 \\
0.5 \\
0.474 \\
0.34\end{array}$ \\
\hline
\end{tabular}

(2) By grit blasting of $0.3 \mathrm{MPa} / 1 \mathrm{~min}$ or $0.5 \mathrm{MPa} / 2 \mathrm{~min}$ and subsequent heat treatment in vacuum at $1100{ }^{\circ} \mathrm{C}$ for $200 \mathrm{~h}$, cellular recrystallization with thickness of $18 \mu \mathrm{m}$ and $49 \mu \mathrm{m}$, respectively, formed at the surface on alloy SXG3 sheet, resulting in the reduction of stress rupture life by about $20 \%$ or $70 \%$ at $980{ }^{\circ} \mathrm{C} / 250 \mathrm{MPa}$, i.e., $186.9 \mathrm{~h}$ and $73.4 \mathrm{~h}$, respectively, compared to the specimen only by vacuum heat treatment at $1100{ }^{\circ} \mathrm{C}$ for $200 \mathrm{~h}$.

(3) Cellular recrystallization is detrimental to the stress rupture property of alloy SXG3 sheet, since they are vulnerable for microcracks to initiate and reduce the effective loading area.

Acknowledgements This work was financially supported by the National Key Research and Development Program of China (Grant No. 2016YFB0701403) and the National Natural Science Foundation of China (Grant No. 91860201).

\section{References}

[1] X. Zhang, H. Li, M. Zhan, Z. Zheng, J. Gao, G. Shao, J. Mech. Sci. Technol. 36, 79 (2020)
[2] H.P. Wang, C.H. Zheng, P.F. Zou, S.J. Yang, L. Hu, B. Wei, J. Mech. Sci. Technol. 34, 22 (2018)

[3] B. Hu, Y.L. Pei, S.K. Gong, H.B. Xu, Acta Metall. Sin. 55, 1204 (2019)

[4] A.W. Zhang, S. Zhang, D. Zhang, W.H. Zhang, D.W. Han, F. Qi, Y. Guo Tan, X. Xin, W.R. Sun, Acta Metall. Sin. (Engl. Lett.) 32, 887 (2019)

[5] X.W. Li, X.G. Liu, Y. Wang, J.S. Dong, L.H. Lou, Acta Metall. Sin. (Engl. Lett.) 32, 651 (2019)

[6] C.M.F. Rae, R.C. Reed, Acta Mater. 55, 1067 (2007)

[7] C. Panwisawas, H. Mathur, J.C. Gebelin, D. Putman, C.M.F. Rae, R.C. Reed, Acta Mater. 61, 51 (2013)

[8] B. Zhang, X. Lu, D. Liu, C. Tao, Mater. Sci. Eng. A 551, 149 (2012)

[9] L.H. Rettberg, T.M. Pollock, Acta Mater. 73, 287 (2014)

[10] J. Meng, T. Jin, X.F. Sun, Z.Q. Hu, Int. J. Min. Met. Mater. 18, 197 (2011)

[11] D.C. Cox, B. Roebuck, C.M.F. Rae, R.C. Reed, Mater. Sci. Technol. 19, 440 (2003)

[12] C.Y. Jo, H.M. Kim, Mater. Sci. Technol. 19, 1671 (2003)

[13] C.Y. Jo, H.Y. Cho, H.M. Kim, Mater. Sci. Technol. 19, 1665 (2003)

[14] J. Meng, T. Jin, X. Sun, Z. Hu, Mater. Sci. Eng. A 527, 6119 (2010)

[15] Z.X. Shi, S.Z. Liu, X.D. Yue, L.J. Hu, W.P. Yang, X.G. Wang, J.R. Li, J. Iron Steel Res. Int. 24, 1059 (2017)

[16] L.C. Zhuo, M. Huang, J.C. Xiong, J.R. Li, J. Zhu, Acta Metall. Sin. 28, 72 (2015) 
[17] B. Zhang, C. Liu, X. Lu, C. Tao, T. Jiang, Rare Met. 29, 413 (2010)

[18] J. Zhang, D. Wang, G. Xie, Y.Z. Shen, L.H. Lou, Acta Metall. Sin. 55, 1077 (2019). (in Chinese)

[19] G. Xie, L. Wang, J. Zhang, L.H. Lou, Metall. Mater. Trans. A 39, 206 (2008)

[20] D. Duhl, in Superalloys II--High Temperature Materials for Aerospace and Industrial Power ed. by C.T. Sims, N.S. Stoloff, W.C. Hagel (Wiley-Interscience, 1987) p.189

[21] V. Seetharaman, A.D. Cetel, Superalloys 2004, 207 (2004)
[22] B. Cassenti, A. Staroselsky, Mater. Sci. Eng. A 508, 183 (2009)

[23] W. Walston, J. Schaeffer, W. Murphy, Superalloys 1996, 9 (1996)

[24] O. Lavigne, C. Ramusat, S. Drawin, P. Caron, D. Boivin, J. Pouchou, Superalloys 2004, 667 (2004)

[25] T. Murakumo, T. Kobayashi, Y. Koizumi, H. Harada, Acta Mater. 52, 3737 (2004)

[26] M. Acharya, G. Fuchs, Mater. Sci. Eng. A 381, 143 (2009)

[27] Y. Zheng, Z. Ruan, S. Wang, Acta Metall. Sin. 31, 325 (1995). (in Chinese) 